\title{
Evolución territorial del comercio de bienes de consumo duradero en la Zona Metropolitana de la Ciudad de México, 1993-2013
}

\section{Territorial evolution of commerce in durable consume goods in Mexico City Metropolitan Area, 1993-2013}

Fermín Alí Cruz Muñoz*

\section{Resumen}

Actualmente la organización territorial de las actividades económicas en las metrópolis tiende a una dispersión que deriva en microconcentraciones altamente discriminantes y especializadas. El objetivo de este artículo es entender la evolución territorial del comercio de bienes de consumo duradero en la Zona Metropolitana de la Ciudad de México de 1993 a 2013. Mediante un análisis microespacial, se corrobora el desarrollo de un proceso de segmentación de los nodos comerciales bajo un patrón metropolitano de concentración. La evolución territorial tiene una clara diferenciación en las distintas zonas de la metrópoli como resultado del nivel socioeconómico de la población, las vialidades principales y la morfología territorial.

Palabras clave: comercio; evolución territorial; Ciudad de México; organización microespacial

* Instituto Politécnico Nacional. Dirección: Lauro Aguirre 120, Colonia Agricultura, Miguel Hidalgo, Ciudad de México, México. Correo: facruzm@ipn.mx ORCID: https://orcid.org/0000-0001-7057-7057 


\begin{abstract}
Nowadays the territorial organization of economic activities in metropolis tends to a sprawl that generates a very high discriminant and specialized microconcentration. The objective of this paper is to understand the territorial evolution of commerce in durable consumer goods in the Mexico City Metropolitan Area from 1993 to 2013. Through a microspatial analysis, it is confirmed the development of a segmentation process of the commercial nodes, in a metropolitan concentration pattern. The territorial evolution has a clear difference in distinct areas of the metropolis as a result of the socioeconomic level of the population, principal avenues and territorial morphology.
\end{abstract}

Keywords: commerce; territorial evolution; Mexico City; microspatial organization.

Tradicionalmente, las investigaciones que buscan entender la forma en que se organiza espacialmente la actividad comercial en el interior de una urbe se apoyan en la teoría del lugar central (Kohsaka, 1986; Yang, 1990; Trullen y Boix, 2003; Grajales, 2006). A partir de numerosos análisis para determinar la pertinencia de este modelo para aplicarlo en la realidad, se han realizado adecuaciones que buscan aproximarse más a las condiciones territoriales, sociales y económicas que caracterizan un entorno urbano.

Dentro del esquema jerarquizado de la actividad comercial, normalmente se ha posicionado a los establecimientos de bienes de consumo duradero ${ }^{1}$ como los responsables de construir los nodos de mayor rango debido a su mayor alcance de mercado (Berry, 1971). Esta investigación parte de la hipótesis de que este tipo de actividad tiene por sí misma un sistema jerarquizado que abarca toda la zona metropolitana y posee cierto grado de independencia con el resto de la actividad comercial debido a la frecuencia de consumo de los bie-

${ }^{1}$ El Banco de México (2019) define a los bienes de consumo duradero como aquellas mercancías que tienen una vida útil mayor a un año y que son demandadas por las familias, empresas y gobierno para su funcionamiento y/o manutención. Cabe aclarar que no se incluyen los bienes adquiridos por las empresas para la producción, los cuales se denominan bienes de capital. 
nes respecto a los de consumo inmediato, y a que los bienes intermedios y de capital son adquiridos principalmente por las empresas.

El objetivo de este trabajo es comprender la dinámica de la organización territorial del comercio de bienes de consumo duradero en la Zona Metropolitana de la Ciudad de México (ZMCM) en el periodo de 1993 a 2013. Con ello se espera entender la evolución de su ocupación en el espacio metropolitano bajo un contexto de expansión de la urbe, y contrastar los resultados con las propuestas de jerarquización derivadas de la teoría del lugar central. Se reconoce que realizar un análisis que busque explicar las causas o los factores de localización queda fuera de la finalidad de este trabajo, pues ello requiere de un análisis más detallado de cada una de las aglomeraciones y de múltiples factores territoriales que han motivado la transformación urbana. No obstante, los hallazgos de este trabajo darán pauta para futuras investigaciones orientadas hacia teorías explicativas.

\section{Modelación espacial de la actividad comercial de bienes de consumo duradero}

Davies (1972) es de los primeros en aplicar la teoría del lugar central (Christaller, 1966) para entender la organización espacial de la actividad terciaria en el interior de las urbes. ${ }^{2}$ Retoma la jerarquización urbana -solar urbano, villa, pueblo, ciudad y metrópoli- para traducirla a una lógica de concentración económica intraurbana -comercio aislado, centro de barrio, subcentro urbano y centro urbano(Esquema 1). El autor reconoce la diferenciación de la calidad de los bienes ofrecidos en función del nivel socioeconómico de la población (Davies, 1972, p. 68), de tal forma que cada nodo de una misma jerarquía puede ofrecer bienes de diferente calidad. Determina cinco categorías de bienes según su calidad (alta, alta-media, media, media-baja y baja), que corresponden con segmentos de población estratificados por niveles socioeconómicos.

${ }^{2}$ Para profundizar en la aplicación de la teoría del lugar central a una escala intraurbana, se puede consultar a Forbes (1972) y a West, Hohenbalken y Kroner (1985). 


\section{Esquema 1}

Hipótesis de la organización jerárquica de los servicios y comercio al consumidor

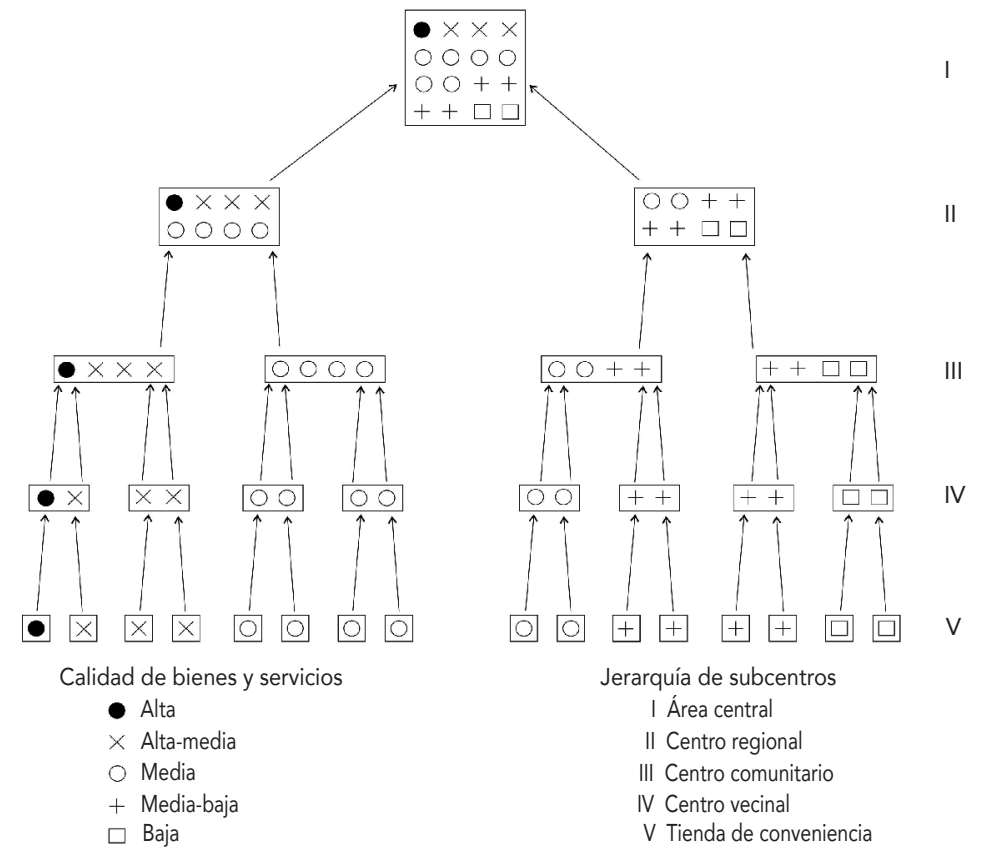

Fuente: Davies, 1972, p. 70.

Esta diversidad de oferta se plasma en la heterogeneidad de la oferta de los diferentes centros de comercio de bienes de consumo duradero. Los centros de menor rango tienen una especialización en cuanto a la calidad de los bienes, mientras que los nodos de mayor jerarquía tienen una mezcla debida al mayor alcance del mercado (Esquema 1).

La diferenciación socioeconómica de la población residente tiene efectos en los patrones de consumo y en especial en el traslado para satisfacer sus necesidades de bienes duraderos (Davies, 1972, p. 69; Potter, 1980, p. 209). La población de mayor ingreso está dispuesta a realizar viajes más largos a fin de adquirir los bienes de consumo duradero, por lo que no necesariamente consumen en los 
centros más cercanos. Esta condición refuerza la posibilidad de aglomeración de los establecimientos al tener una amplia área de atracción de la población consumidora.

En contraste, la población de menor ingreso tiende a realizar viajes más cortos para satisfacer la misma necesidad. Esto tiene implicaciones en la proximidad de los establecimientos, derivando en un mayor número de centros locales y de fácil acceso por el transporte colectivo. Esta condición debilita las fuerzas centrípetas para la formación de nodos de mayor jerarquía en favor de los de menor rango. Tal diferencia de comportamiento de consumo altera el sistema y debería generar una diferenciación en la jerarquía y en la cantidad de nodos que atienden a los diferentes segmentos del mercado metropolitano, aunque no lo expresa Davies (1972) en su esquema (véase el Esquema 1).

En la propuesta de Berry (1971, p. 361) se clasifica la actividad terciaria según su jerarquía y se incorpora a los corredores urbanos (Esquema 2). Berry también retoma la jerarquía de los nodos comerciales, donde define al centro metropolitano como la mayor concentración, y a la tienda de conveniencia como la opción de menor jerarquía y más dispersa. Cabe aclarar que, para los bienes de consumo duradero, no sería adecuado utilizar el término de tiendas de conveniencia pues éstas hacen referencia a la oferta de bienes de consumo inmediato. No obstante, sí sería posible considerar la existencia de establecimientos de alcance local que ofrezcan bienes de consumo duradero. Asimismo, Berry vincula la constitución de centros regionales como aquellos espacios donde se ofrecen los bienes de consumo duradero especializados y que tienden a localizarse en la zona central.

En relación a la formación de los corredores urbanos, la clasificación la realiza en cuatro tipos -calle comercial tradicional, arteria urbana, nueva franja suburbana y vías rápidas-. Si bien no necesariamente esta tipología tiene una jerarquización completamente definida, sí determina que algunos de esos corredores son equivalentes a determinados niveles jerárquicos de los centros. Las vialidades producen una accesibilidad física diferenciada a escala metropolitana, y por ende, una diferenciación entre los corredores (Berry, 1971, p. 361). A diferencia de los centros, Berry no los jerarquiza en función 
de su alcance en el mercado; los corredores son una manifestación morfológica que puede insertarse en los diferentes niveles de los centros (Esquema 2).

\section{Esquema 2}

Clasificación de los servicios y comercio según su localización

Centros

Planeados o no planeados

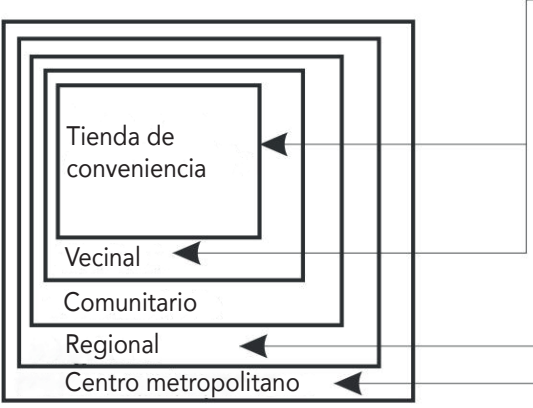

Corredores

Calle comercial tradicional

Arteria urbana

Nueva franja suburbana

Vías rápidas: planeadas (plazas) y no planeadas

\section{Fuente: Berry, 1971, p. 362.}

En primera instancia, están los corredores que se encuentran a lo largo de las tradicionales calles comerciales locales. Las concentraciones sobre las principales arterias urbanas son la segunda tipología y tienen la capacidad de atraer establecimientos comerciales de bienes de consumo duradero. El tercer tipo son las franjas suburbanas que responden a la misma lógica que los corredores que se encuentran en las vías primarias. El cuarto tipo de corredor se encuentra en las vías rápidas y se constituye por establecimientos que ofrecen bienes al medio mayoreo, como los outlets.

Si bien estos postulados no han sido discutidos por la literatura más actual, sí se han realizado reflexiones más vigentes sobre la forma en que la actividad comercial se constituye en el territorio. Esta discusión yace bajo la visión del actual proceso de fragmentación espacial que reconoce Burgess (2011, p. 64). Tal fragmentación se vincula con un seccionamiento de la estructura de las urbes. El primer proceso de relativa independencia funcional lo destaca Gaschet 
(2002, p. 64) con el declive del centro urbano, que es sustituido por los subcentros que se encuentran en las zonas suburbanas. Ello implica que la población ya no requiere acudir al centro urbano para satisfacer su necesidad de bienes de consumo.

Este proceso de descentralización territorial no ha cesado, lo que ha derivado en una tendencia hacia la dispersión de la actividad económica. En primera instancia, el policentrismo se manifestaba como una etapa inicial que posteriormente favorecería la ubicuidad de la actividad en toda la zona urbana (Lang, 2003).

Borsdorf (2003) explica esta aparente dispersión a partir de una superespecialización funcional de la ciudad, que se genera a partir de múltiples centros especializados, pero fuertemente discriminantes (Link, 2008, p. 15), ajustándose a la propuesta de Davies (1972). Estos agrupamientos se manifiestan territorialmente en una menor escala a los tradicionales distritos o núcleos definidos por Hoyt (1939), así como por Harris y Ullman (1945). Ello obliga a reflexionar sobre la metodología de análisis de la estructura urbana de las zonas metropolitanas. Implica un análisis vinculado a la multiescalaridad que deriva del tamaño creciente de las urbes y de la fragmentación funcional de las mismas.

La aglomeración de actividades similares sigue siendo un proceso vigente y su supervivencia depende de los vínculos construidos con el mercado adyacente. No obstante, esta lógica se aplica a una escala local, la cual no necesariamente es de alcance metropolitano. La fragmentación urbana implica una dualidad de procesos territorializados de ocupación del suelo que puede entenderse desde una perspectiva metropolitana, pero también requiere analizarse a menor escala.

Esta visión se sustenta en la nueva forma en que se están construyendo los nodos comerciales. Desde el punto de vista de la planeación, se tiene una tendencia denominada por Lerner (2005) como la "acupuntura urbana", donde proyectos específicos buscan orientar el ordenamiento territorial a una escala local. Desde el punto de vista de la implementación de dicho mecanismo de "ordenamiento" urbano, el sector inmobiliario se ha posicionado como el elemento clave. La reconfiguración de la ciudad se vincula con el desarrollo de megaproyectos urbanos y macroedificaciones (Prévôt, 2001, p. 46). 
Esta reconfiguración se vincula al proceso de reciclamiento urbano en zonas específicas que responden a mercados intraurbanos. En el caso de la actividad comercial de bienes de consumo duradero, los shopping centers han representado una atractiva fuente de oferta de espacio adaptado, generando las condiciones propicias para el desarrollo de economías de aglomeración. Simmons, Kamikihara y Garrocho (2016) dimensionan la aportación que tiene este comercio, que denominan como moderno, frente al tradicional, donde es clara su mayor aportación en las ventas.

\section{Metodología: indicadores para determinar la evolución de patrón territorial}

La organización espacial del comercio puede describirse mediante su configuración, que es una representación territorial de la manifestación de la actividad (Munizaga, 2000). La configuración muestra una realidad observable y medible que empírica y deductivamente se interpreta como una expresión de los procesos de localización en intensidad de actividades económicas. Para determinar la organización espacial de la actividad comercial, se medirá la magnitud que se realiza en un lugar. La actividad económica se puede definir como la combinación de recursos que permiten, bajo un procedimiento o conjunto de tareas, la generación de bienes o la prestación de servicios (INEGI, 1999). Kevin Lynch (1981) menciona que la actividad no solamente se limita a la acción humana, ya que en la ciudad es necesario considerar también las acciones de las máquinas, por lo que se requiere tomar en cuenta todo el sistema en cuestión.

Por lo tanto, la variable a emplear para esta investigación, dado que el objetivo de la actividad económica es la producción de bienes y servicios, considerará al valor de dicha producción, utilizando la variable valor agregado censal bruto (VACB). El Instituto Nacional de Geografía y Estadística (INEGI) define esta variable como:

[...] el valor de la producción que se añade durante el proceso de trabajo, por la actividad creadora y de transformación del personal ocupado, 
el capital y la organización (factores de la producción), ejercida sobre los materiales que se consumen en la realización de la actividad económica [INEGI, 2004, p. 42].

Las fuentes de información son los censos económicos de 1994 y 2014, que presentan datos de 1993 y 2013, respectivamente. El dato base será el valor agregado censal bruto, aunque también se incorporarán los datos relacionados con las unidades económicas y el personal ocupado, con el objetivo de calificar los establecimientos.

Para determinar los establecimientos que realizan comercio de bienes de consumo duradero, se considerarán aquellos que en el ordenamiento del Sistema de Clasificación Industrial de América del Norte (SCIAN) ofrezcan un bien reutilizable. Esta subclasificación responde a los estudios realizados en la ZMCM que han dado patrones espaciales diferenciados, y a las teorías que sustentan dichos patrones de localización. La metodología para clasificar el sector económico de los censos es retomada de Garza (2008). ${ }^{3}$

La unidad geográfica de análisis es el área geoestadística básica (AGEB) urbana, definida como la unidad fundamental del marco geoestadístico del INEGI. Esta unidad de análisis permite determinar con un mayor nivel de desagregación los patrones espaciales, pudiendo identificar las microdiferencias de la concentración económica. Precisamente fue en 1994 cuando se realizó el primer censo económico con este nivel de desagregación, lo que permite ahora contrastar sus datos con los levantados en 2014. Se espera que el plazo de veinte años sea suficiente para encontrar procesos y tendencias de desplazamiento y reorganización espacial de la actividad económica en el interior de la ZMCM bajo un contexto de desindustrialización.

Es claro que los límites de la zona metropolitana han cambiado en este lapso y, por ende, su superficie ha aumentado. En 1993 la zona metropolitana estaba constituida por las 16 delegaciones del Distrito Federal y por 29 municipios del Estado de México. ${ }^{4}$ La su-

${ }^{3}$ Para conocer las ramas de actividad económica que conforman el comercio de consumo duradero se puede consultar a Garza (2008), donde se desglosa a detalle.

${ }^{4}$ En 1993 la ZMCM estaba constituida por 16 delegaciones: 09002, Azcapotzalco; 09003, Coyoacán; 09004, Cuajimalpa de Morelos; 09005, Gustavo A. Ma- 
perficie de la zona metropolitana se conformaba por 4738 AGEB y representaba un área de 194145 hectáreas. Cabe destacar que esta área cuantifica solamente las AGEB urbanas, por lo que permite tener una estimación de la extensión de la zona metropolitana muy precisa.

Veinte años después, la zona metropolitana se compone por las 16 delegaciones del Distrito Federal, 59 municipios del Estado de México y uno del estado de Hidalgo. ${ }^{5}$ Como resultado de esta nueva delimitación y por la expansión urbana, se totalizan 5694 AGEB que representan un área de 229706 hectáreas. La expansión metropolitana tuvo una tasa de crecimiento media anual de $18 \%$, donde la zonas norte y sur-oriente son las principales áreas de expansión de la metrópoli (Mapa 1).

dero; 09006, Iztacalco; 09007, Iztapalapa; 09008, La Magdalena Contreras; 09009, Milpa Alta; 09010, Álvaro Obregón; 09011, Tláhuac; 09012, Tlalpan; 09013, Xochimilco; 09014, Benito Juárez; 09015, Cuauhtémoc; 09016, Miguel Hidalgo; y 09017, Venustiano Carranza. Asimismo, por los municipios conurbados del Estado de México: 15002, Acolman; 15011, Atenco; 15013, Atizapán de Zaragoza; 15020, Coacalco de Berriozábal; 15024, Cuautitlán; 15025, Chalco; 15028, Chiautla; 15029, Chicoloapan; 15030, Chiconcuac; 15031, Chimalhuacán; 15033, Ecatepec de Morelos; 15037, Huixquilucan; 15039, Ixtapaluca; 15044, Jaltenco; 15053, Melchor Ocampo; 15057, Naucalpan de Juárez; 15058, Nezahualcóyotl; 15059, Nextlalpan; 15060, Nicolás Romero; 15070, La Paz; 15081, Tecámac; 15091, Teoloyucan; 15095, Tepotzotlán; 15099, Texcoco; 15104, Tlalnepantla de Baz; 15108, Tultepec; 15109, Tultitlán; 15102, Zumpango; y 15121, Cuautitlán Izcalli (Conapo, 1994).

${ }^{5} \mathrm{La}$ ZMCM se conformaba en 2013 por las mismas 16 delegaciones y por los municipios del Estado de México mencionados en la nota anterior, más: 15009, Amecameca; 15010, Apaxco; 15015, Atlautla; 15016, Axapusco; 15017, Ayapango; 15022, Cocotitlán; 15034, Ecatzingo; 15035, Huehuetoca; 15036, Hueypoxtla; 15038, Isidro Fabela; 15046, Jilotzingo; 15050, Juchitepec; 15061, Nopaltepec; 15065, Otumba; 15068, Ozumba; 15069, Papalotla; 15075, San Martín de la Pirámides; 15083, Temamatla; 15084, Temascalapa; 15089, Tenango del Aire; 15092, Teotihuacán; 15093, Tepetlaoxtoc; 15094, Tepetlixpa; 15096, Tequixquiac; 15100, Tezoyuca; 15103, Tlalmanalco; 15112, Villa del Carbón; 15122, Valle de Chalco Solidaridad y Tonantila; así como 13069, Tizayuca, del municipio de Hidalgo (Sedesol, Conapo e INEGI, 2012). 


\section{Mapa 1}

Zona Metropolitana de la Ciudad de México: expansión de la zona urbana, 1993-2013

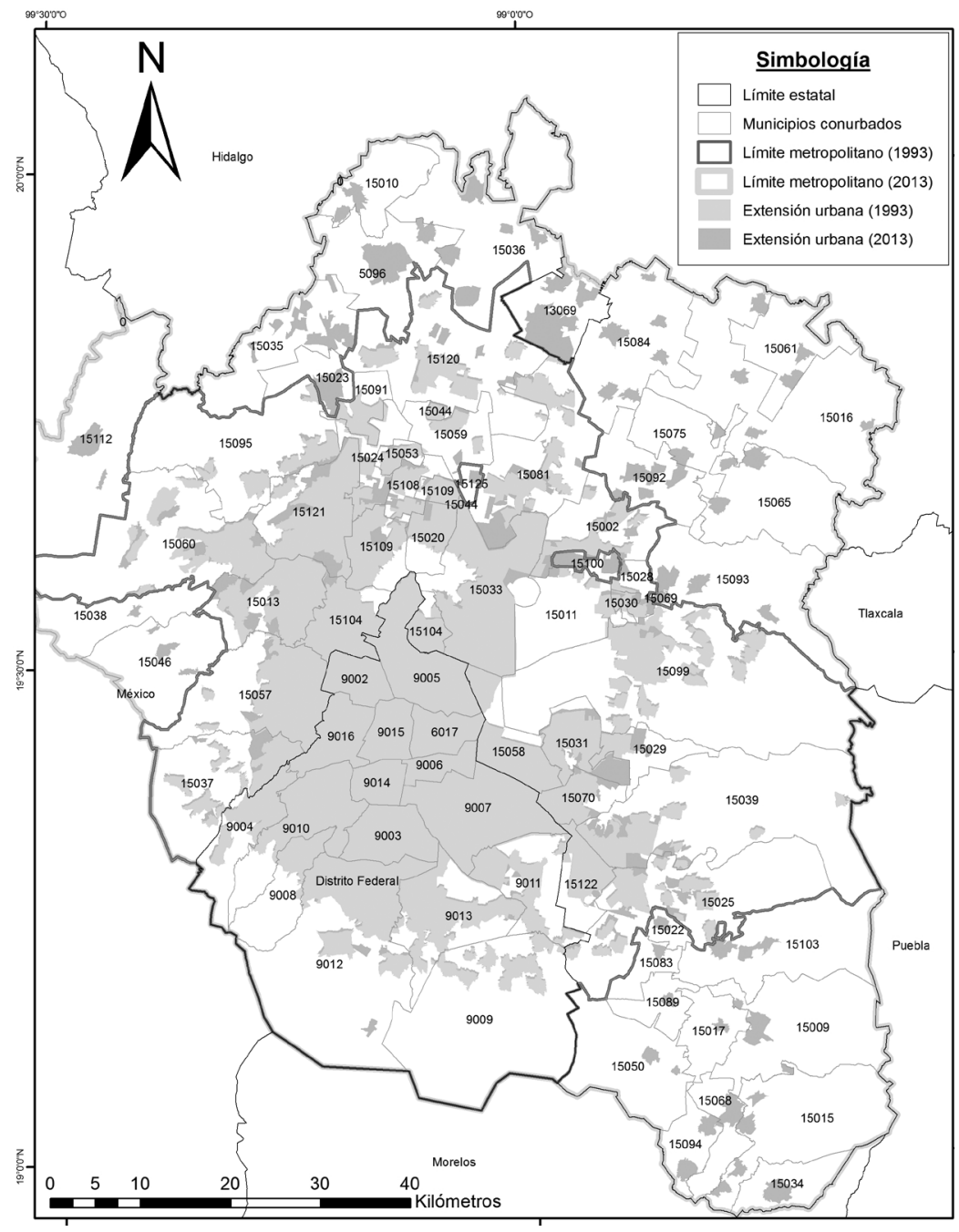

Fuente: Elaboración propia a partir del Marco Geoestadístico Nacional, 1995 y 2013, INEGI. 
A fin de realizar la comparación espacio-temporal de la actividad económica, se construyó un sistema de información geográfica donde se hizo un ajuste de las AGEB que se modificaron. La gran mayoría de los casos fueron áreas que se subdividieron, por lo que los datos del VACB del censo económico de 1994 del área en cuestión se dividieron en proporción a las nuevas áreas creadas por dicha subdivisión.

El otro elemento a considerar es la comparabilidad de datos intercensales, por la diferenciación de clasificaciones en los censos económicos. Por un lado, el censo económico de 1994 se basó en la Clasificación Mexicana de Actividades y Productos (CMAP). Para el censo de 2018 se utilizó el SCIAN. Estas clasificaciones diferenciadas entre censos requirieron revisar detenidamente las tablas comparativas entre los censos elaboradas por el INEGI,${ }^{6}$ con el objetivo de realizar una comparación adecuada.

Para realizar el análisis espacial, se utilizó como indicador inicial el índice de Hoover, que cuantifica el grado de concentración de un fenómeno en el espacio, y su ventaja frente a otros índices es que puede ser ponderado por la superficie de la unidad espacial de análisis. Esta cualidad es muy conveniente para el caso de estudio debido a que las áreas geoestadísticas básicas que constituyen la ZMCM son muy heterogéneas. El área más pequeña es de 0.2 hectáreas, mientras que la más grande es de 73.9 mil hectáreas. Para estimar el índice de Hoover se utiliza la siguiente ecuación:

$$
I H=\frac{1}{2}\left|\sum \frac{P I B_{i a}}{P I B_{i t}}-\frac{A_{a}}{A_{t}}\right|
$$

donde $I H$ es el índice de Hoover; $P I B_{i a}$ es la producción del sector $i$ del AGEB $a ; P I B_{i t}$ es la producción del sector $i$ en toda el área metropolitana; $A_{a}$ es el área del AGEB; y $A_{t}$ es el área total de la zona metropolitana.

${ }^{6}$ Por los límites de extensión del artículo, no se incluyó el cuadro comparativo, pero es posible contactar al autor para su consulta. 
El rango del índice es de uno a cero y determina el grado de concentración, por lo que se considerará para este análisis de $0-0.25$ como una organización muy dispersa; de $0.251-0.50$, como una distribución moderadamente dispersa; de 0.51-0.75, como una configuración moderadamente concentrada; y de 0.751-1, como una localización muy concentrada.

Para el análisis longitudinal, se utilizó la técnica de "Cambio y participación", también conocida como Shift \& Share, que se calcula de la siguiente manera:

$$
X_{i j} g_{i j}=X_{i j} G+X_{i j}\left(G_{i}+G\right)+X_{i j}\left(g_{i j}-G_{i}\right)
$$

donde $X_{i j}$ representa la producción del sector $i$ en el AGEB $j$ en 1993; $g_{i j}$ es la tasa de crecimiento media anual de la producción en el sector $i$ en el AGEB $j$ de 1993 a 2013; $G_{i}$ representa la tasa metropolitana de crecimiento media anual de la producción en el sector $i$ de 1993 a 2013; y $G$ es la tasa metropolitana de crecimiento media anual de la actividad terciaria de 1993 a 2013 (Ramajo y Márquez, 2008).

Esta técnica permite discriminar el efecto local sobre el metropolitano y sectorial a fin de conocer los cambios resultantes de las condiciones particulares de cada unidad espacial. El dato que se analiza es el cambio local definido por el último sumando, cuyo valor positivo indica un efecto local de atracción de la actividad económica, y un valor negativo significa expulsión de la actividad comercial por razones locales.

\section{Organización territorial del comercio de bienes de consumo duradero}

La actividad comercial de bienes de consumo duradero tiene una organización microespacial altamente concentrada que se mantiene a lo largo del periodo de análisis. En 1993 el índice de Hoover fue de 0.7509 , mientras que en 2013 tuvo un muy ligero incremento al registrar 0.7527 . Esto tiene implicaciones interesantes porque, a diferencia de lo que marca la teoría sobre un proceso de dispersión (Dematteis y Governa, 2001, p. 29), se mantiene la concentra- 
ción espacial. Esta tendencia se observa con los datos que muestra el Cuadro 1, donde se identifica un incremento en la participación de las AGEB con muy alta producción. En 1993 las AGEB con muy alta producción representaban $1.28 \%$ de la superficie metropolitana y concentraban poco más de $36 \%$ de la producción. En un lapso de veinte años, este tipo de AGEB representa $1.68 \%$ del área urbana y poco más del $40 \%$ de la producción.

En contraste, las zonas sin actividad comercial en 1993 eran 36\% del total de la superficie urbana. Si bien en 2013 esta superficie se redujo, sigue siendo una importante proporción al representar poco menos del 20\%. Esta área sin actividad refuerza la expresión territorial hacia la concentración de la actividad económica en la zona metropolitana. Por un lado, menos del $2 \%$ del territorio concentra más del $40 \%$ de la actividad y, por el otro, casi $20 \%$ no registra producción.

La mayoría de la superficie aporta una muy discreta proporción de la actividad comercial. En 1993, casi 49\% de la superficie registró una producción muy baja y acumuló menos del 12\%. En 2013, poco más del $62 \%$ de la superficie se clasifica en ese mismo nivel de producción, con casi $14 \%$ de la producción metropolitana en comercio de bienes de consumo duradero (Cuadro 1).

Es innegable que este tipo de actividad comercial mantiene la concentración espacial con una muy extensa superficie de actividad muy baja. No obstante, hace falta revisar con mayor detalle su expresión en el territorio metropolitano. Ésa será la labor de los siguientes acápites.

\section{Discreta centralización territorial del comercio en 1993}

La concentración de la actividad comercial de bienes de consumo duradero se manifiesta a partir de un patrón policéntrico. Este patrón es resultado de la formación de once nodos que concentran más de la mitad de la producción metropolitana. Asimismo, existen solamente cinco nodos aislados donde se encuentra una AGEB con muy alta producción sin colindantes con producción superior a la media. Ello muestra la tendencia de aglomeración de esta actividad comercial, 


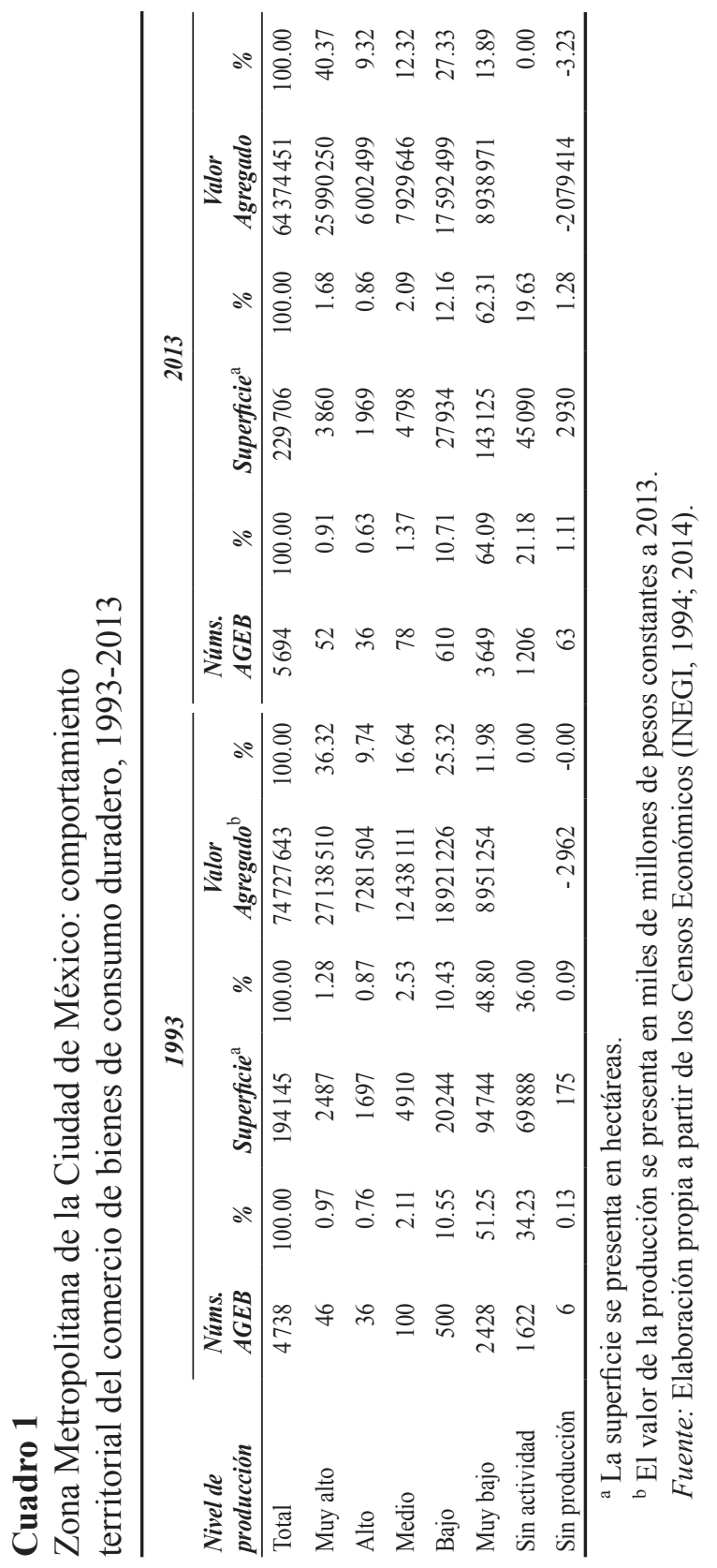


que además muestra evidencia de la importancia de la zona central como concentradora de la producción. Tal centralización se manifiesta dado que el nodo Zona Centro es el más importante en cuanto a extensión, producción e intensidad. Este nodo aporta casi $29 \%$ de la producción metropolitana en una superficie de casi dos mil hectáreas y una intensidad de producción de poco más de $\$ 11$ mil millones por hectárea (Cuadro 2). En el Mapa 2 se observa que este nodo central se extiende hacia la zona sur-poniente, con una ramificación hacia la zona poniente, como resultado de la localización de la población con mayor poder adquisitivo que se encuentra en la urbe. ${ }^{7}$

El segundo nodo de mayor producción es denominado Insurgentes Sur debido a que gran parte del mismo se desarrolla a lo largo de esta importante avenida. No obstante, la morfología del nodo no es propiamente un corredor comercial debido a que tiene una derivación hacia el norte, que se expande a una zona más amplia. En el otro extremo se enlaza con Avenida Universidad, con la cual también se extiende dicho nodo hasta llegar a la intersección de ambas avenidas (Mapa 2).

En el Cuadro 2 se puede observar que este nodo, además de ser el segundo con mayor generación de valor agregado al aportar casi $10 \%$ de la producción metropolitana, también es el segundo más extenso con casi mil hectáreas. Es clara la diferencia entre este nodo con la Zona Centro, pues produce casi un tercio respecto al nodo central y no alcanza la misma intensidad de producción. No obstante, representa una concentración que abastece a las colonias de la zona centro-sur caracterizadas por un alto nivel socioeconómico.

El tercer nodo también se encuentra en la zona sur, y se le llamó Periférico Sur debido a que corre a lo largo de esta importante vía rápida. A diferencia del caso anterior, este nodo sí podría considerarse como un corredor comercial. Tiene una dimensión mucho menor en comparación a los previos casos, lo que deriva en un incremento de su intensidad de producción, siendo la segunda mayor después del nodo central. Este nodo también se caracteriza por albergar los

${ }^{7}$ Aguilar y Mateos (2011) realizan un análisis muy detallado sobre la organización sociodemográfica de la población en la Zona Metropolitana de la Ciudad de México, sobre el cual se basaron los argumentos de este análisis. 
establecimientos con mayor tamaño en cuanto a personal ocupado, con casi 34 empleados por unidad económica (Cuadro 2). Estas dos cualidades posicionan a este nodo como uno de los más importantes, al ser compacto y con unidades comerciales de gran tamaño. Esto se explica porque ahí se encuentra el principal centro comercial, al registrar las mayores ventas de todos los centros comerciales de México (Celis y Pantaleón, 2016).

\section{Cuadro 2}

Zona Metropolitana de la Ciudad de México: cualidades generales de los nodos comerciales de bienes de consumo duradero, 1993

\begin{tabular}{|c|c|c|c|c|c|c|}
\hline \multirow[b]{2}{*}{$\begin{array}{l}\text { Agrupaciones } \\
\text { espaciales }\end{array}$} & \multicolumn{2}{|c|}{ Valor agregado ${ }^{\mathrm{a}}$} & \multicolumn{2}{|c|}{ Area } & \multirow[b]{2}{*}{$\begin{array}{c}\text { Intensidad }^{\text {Inteducción }}{ }^{\mathrm{b}} \\
\text { produs }^{2}\end{array}$} & \multirow{2}{*}{$\begin{array}{c}\text { Personal } \\
\text { por unidad } \\
\text { económica }\end{array}$} \\
\hline & $\begin{array}{l}\text { Miles de } \\
\text { millones }\end{array}$ & $\%$ & Hectáreas & $\%$ & & \\
\hline Total de la actividad & 74728 & 100.00 & 194145 & 100.00 & 0.38 & 2.67 \\
\hline Total de nodos & 39237 & 52.51 & 5665 & 2.92 & 6.93 & 4.32 \\
\hline 1. Zona Centro & 21263 & 28.45 & 1908 & 0.98 & 11.14 & 3.58 \\
\hline 2. Insurgentes Sur & 7248 & 9.70 & 937 & 0.48 & 7.74 & 7.92 \\
\hline 3. Periférico Sur & 2619 & 3.51 & 254 & 0.13 & 10.31 & 33.90 \\
\hline 4. Satélite & 1968 & 2.63 & 293 & 0.15 & 6.72 & 8.09 \\
\hline 5. Naucalpan Centro & 1274 & 1.70 & 558 & 0.29 & 2.28 & 6.33 \\
\hline $\begin{array}{l}\text { 6. Tlalnepantla } \\
\text { Centro }\end{array}$ & 1200 & 1.61 & 470 & 0.24 & 2.55 & 3.80 \\
\hline 7. Villa Coapa & 1108 & 1.48 & 132 & 0.07 & 8.39 & 3.94 \\
\hline 8. Aeropuerto & 1102 & 1.47 & 776 & 0.40 & 1.42 & 4.33 \\
\hline 9. Lindavista & 600 & 0.80 & 82 & 0.04 & 7.31 & 10.35 \\
\hline 10. La Villa & 458 & 0.61 & 130 & 0.07 & 3.52 & 2.19 \\
\hline 11. Torres Lindavista & 397 & 0.53 & 125 & 0.06 & 3.17 & 18.80 \\
\hline Total de nodos aislados & 1781 & 2.38 & 597 & 0.31 & 2.98 & 9.37 \\
\hline 1. Interlomas & 512 & 0.69 & 135 & 0.07 & 3.80 & 6.01 \\
\hline 2. Ticomán & 415 & 0.56 & 233 & 0.12 & 1.78 & 89.33 \\
\hline 3. San Jerónimo & 312 & 0.42 & 139 & 0.07 & 2.24 & 11.65 \\
\hline 4. Plaza Aragón & 293 & 0.39 & 60 & 0.03 & 4.88 & 5.74 \\
\hline 5. Santa Cruz Coyuya & 249 & 0.33 & 30 & 0.02 & 8.29 & 4.96 \\
\hline
\end{tabular}

${ }^{\text {a }}$ Los valores se presentan en pesos constantes a 2013.

${ }^{\mathrm{b}}$ La intensidad de producción está expresada en valor agregado en miles de millones de pesos constantes a 2013 por hectárea.

Fuente: Elaboración propia a partir del Censo Económico (INEGI, 1994). 


\section{Mapa 2}

Zona Metropolitana de la Ciudad de México: organización territorial del comercio de bienes de consumo duradero, 1993

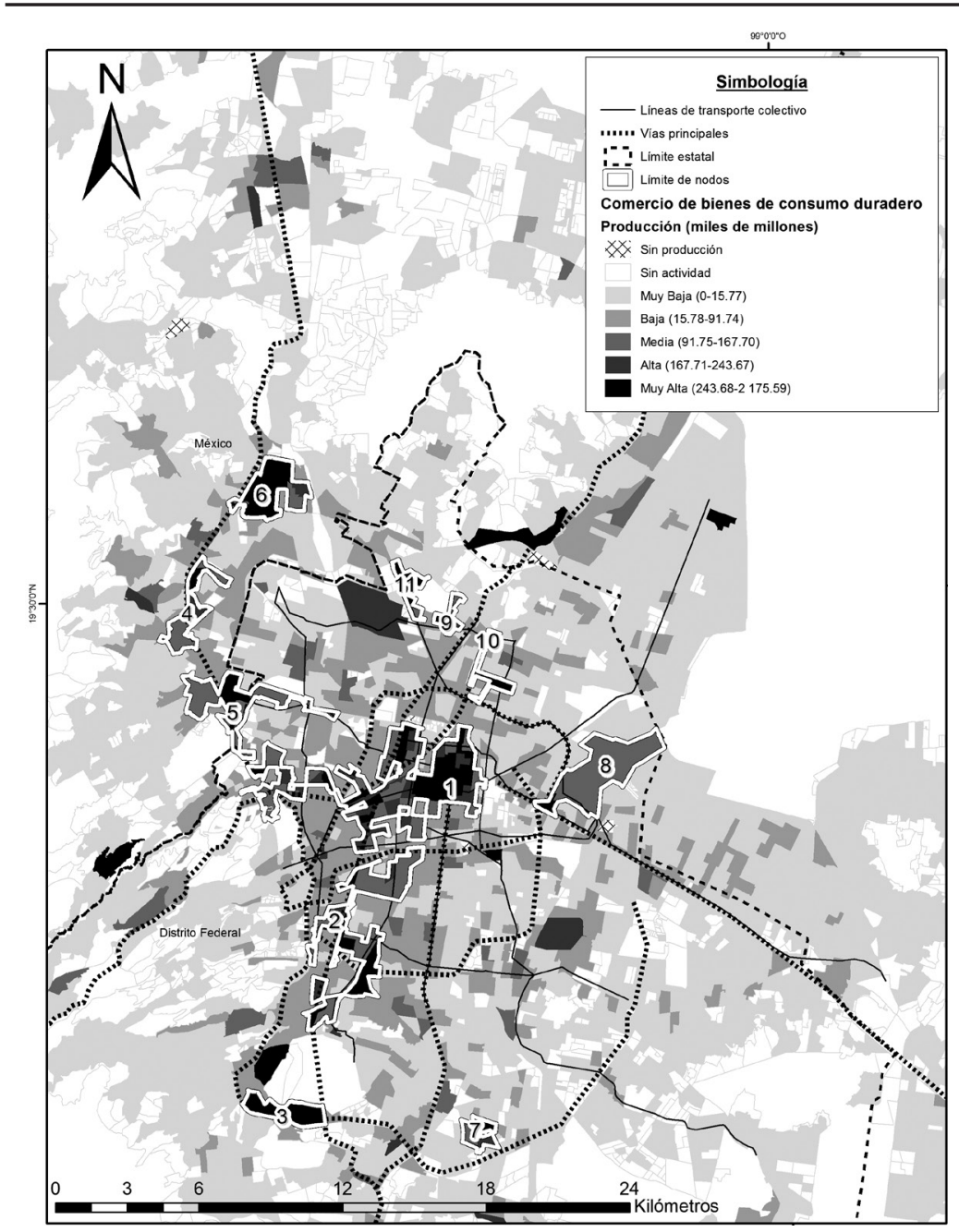

Fuente: Elaboración propia a partir del Censo Económico (INEGI, 1994). 
Los siguientes tres nodos de mayor producción se emplazan en la zona norponiente. Como se puede observar, la predominancia de los nodos se ubica en la zona centro-poniente, donde solamente los nodos de Aeropuerto y Villa Coapa se encuentran ligeramente cargados hacia la zona centro-oriente y sur-oriente, respectivamente. Este patrón de emplazamiento responde esencialmente a la localización de la población con mayor poder adquisitivo.

Respecto a la localización de los cinco nodos aislados, la mayoría se encuentra en la zona oriente, aunque Interlomas, localizado en la zona poniente, registra la mayor producción. Este nodo se encuentra en el corazón de la zona de mayor poder adquisitivo de la metrópoli, por lo que es el único que justifica su alta proximidad. Es decir, la velocidad de renovación de los bienes de consumo duradero es mayor debido a que este segmento de población tiene el poder adquisitivo para sustituir estos bienes sin esperar a que termine su vida útil. El resto de los nodos, y en especial los que abarcan más de una AGEB, tienden hacia la centralización y estrecha proximidad a las vías más importantes de la urbe.

Los nodos de Periférico Sur, Satélite, Naucalpan Centro y Tlalnepantla Centro se localizaron sobre Anillo Periférico. Los nodos de Insurgentes Sur y Lindavista tienen su emplazamiento sobre Avenida de los Insurgentes. Otros nodos, como Villa Coapa, La Villa y Torres Lindavista, se encuentran a menos de cinco minutos de estas mismas avenidas importantes. Para el caso del nodo Zona Centro, si bien su origen se explica a partir del proceso histórico de concentración comercial en dicha zona, su morfología se entiende también por el trazo de esas dos avenidas importantes pues este nodo se extiende hasta llegar a las dos vías mencionadas. Es clara la trascendencia de estas dos arterias metropolitanas de la zona poniente para entender el emplazamiento de los nodos comerciales.

Ahora se busca analizar el tipo de nodo a partir de los factores que favorecieron el agrupamiento. La tipología se clasifica por plazas comerciales, outlets y agrupamientos de establecimientos aislados. Respecto al tipo de establecimiento, es complejo determinar una predominancia debido a la extensión de los nodos que favorece la diversidad. Zona Centro, Insurgentes Sur, Aeropuerto, Lindavista y La Villa representan la última tipología, con una agrupación de múlti- 
ples establecimientos que se entienden por la convergencia de avenidas y, adicionalmente, en el caso de la Zona Centro, por su histórica concentración de actividad económica.

Por otro lado, los nodos de Periférico Sur, Satélite y Villa Coapa se constituyen por la presencia de una plaza comercial que ha tenido la capacidad de atraer actividad comercial en los alrededores. Esto muestra la importancia de Perisur, Plaza Satélite y Galerías Coapa para entender la formación de dichos nodos, pues se identifica una gran cantidad de establecimientos comerciales que se encuentran fuera de las plazas.

La tercera tipología se explica por la presencia de la actividad industrial y/o grandes zonas de almacenamiento de las empresas manufactureras de bienes de consumo duradero. Naucalpan Centro, Tlalnepantla Centro y Torres Lindavista se localizan en zonas industriales que facilitan la generación de establecimientos comerciales de las mismas empresas fabriles para ofrecer sus productos a menores precios que los que generalmente se ofrecen en las tiendas departamentales o especializadas. Esta condición favorece la presencia de outlets.

En lo que se refiere a los nodos aislados, es más fácil determinar el tipo de establecimientos que constituyen la agrupación al ser más pequeños. Nodos como Interlomas, San Jerónimo y Plaza Aragón se forman gracias a las plazas comerciales ahí construidas. En el caso del nodo de Ticomán, se trata de un outlet, y en Santa Cruz Coyuya se ha formado una aglomeración de diversos establecimientos por la convergencia de vías importantes, como Viaducto Río de la Piedad y Eje 3 Oriente.

Es claro el patrón de la actividad comercial de bienes de consumo duradero durante la última década del siglo XX, en el que once nodos forman un patrón policéntrico. Dentro del área metropolitana es también evidente la localización de dichos nodos en la zona centro-semiperiferia poniente, como resultado de la localización de la población de mayor poder adquisitivo. En lo particular, el emplazamiento de los nodos se explica por dos vías vehiculares de trascendencia metropolitana: Anillo Periférico y Avenida de los Insurgentes. En algunos casos, la construcción de una plaza comercial o de zonas industriales ha favorecido la agrupación. Ahora se analizará la transformación de este patrón veinte años después. 


\section{Segmentación territorial al inicio de la segunda década del siglo XXI}

Tal y como se había comentado al inicio de esta sección, la actividad comercial de bienes de consumo duradero mantiene un patrón hacia la concentración. No obstante, se identifica una transformación territorial en la formación de los nodos (Mapa 3) y una pérdida relativa de su aportación a la producción metropolitana, pues de aportar casi $53 \%$ del valor agregado, ahora sólo aportan 43\% (Cuadro 3), con 1o que baja el umbral que permitía afirmar que la mayoría de la producción se realizaba en los nodos.

Como se puede observar en el Mapa 3, se identifica la formación de quince nodos comerciales que en su mayoría son producto de los nodos existentes previamente. Con excepción de los nodos de Santa Fe, Vallejo y Central de Abasto, el resto tiene su antecedente a los identificados en 1993. No obstante, se observa un proceso de segmentación de los dos nodos de mayor importancia y extensión. Ahora el nodo de la Zona Centro disminuye en tamaño ya que, de casi dos mil hectáreas, tiene poco más de mil hectáreas. Consecuentemente, su participación en la producción metropolitana ha disminuido al pasar de 28 a 16\%. Este nodo puede describirse como dos subcentros (Centro Histórico y Polanco) enlazados por un corredor comercial que se desarrolla a lo largo del Paseo de la Reforma (Mapa 3).

Por otro lado, el nodo de Insurgentes Sur se ha segmentado completamente para resultar en cuatro nodos de menor tamaño (Narvarte Norte, Del Valle, Insurgentes Sur y Chimalistac). Ello ha ocasionado que el nodo Periférico Sur se posicione como la segunda concentración más importante a escala metropolitana. Esta posición la logra sin tener un incremento relativo ni absoluto de la producción, a pesar del aumento de superficie (Cuadro 3) al absorber el nodo aislado de San Jerónimo (Mapa 3). Esta ampliación corresponde a la trascendencia que tiene la vía rápida para consolidar un corredor comercial más extenso.

La tercera agrupación es Satélite, la cual tampoco tiene un incremento significativo en la generación de valor agregado comercial (Cuadro 3) y tiene un ligero crecimiento en su extensión. La cuarta concentración es Narvarte Norte y, como se comentó previamente, deriva de lo que fue el gran nodo de Insurgentes Sur. Esta aglomera- 
ción destaca porque registra la mayor intensidad de producción, con \$20 mil millones por hectárea. Por otro lado, destaca Villa Coapa con el tamaño promedio de establecimiento más grande, con 17 empleados por unidad comercial. Asimismo, registra la segunda mayor intensidad de producción, con $\$ 13$ mil millones por hectárea.

En términos generales, se observa una segmentación de los nodos que mayoritariamente tienen en su interior una o varias plazas comerciales y un área de influencia que deriva en una producción comercial superior a la media. Los nodos de Periférico Sur, Satélite, Narvarte Norte, Santa Fe, Villa Coapa, Del Valle, Lindavista, Plaza Aragón y Chimalistac tienen en su zona de muy alta producción una plaza comercial.

A diferencia del corte temporal anterior, cuando se identificaron cuatro concentraciones que podían explicarse por la presencia de outlets, ahora solamente se identifican dos nodos: Tlalnepantla Centro y Vallejo. Este fenómeno puede estar vinculado con el proceso de desindustrialización de zonas semiperiféricas, que pasan de tener fábricas a zonas de almacenaje y, finalmente, puntos de venta de fabricantes.

Por otro lado, se conserva la Zona Centro como el nodo de mayor aglomeración con una gran diversidad de establecimientos, cuya explicación se vincula con la histórica concentración de actividad comercial. De manera muy diferente, pero también con una gran diversidad de establecimientos, se tiene el nodo de San Antonio, que, si bien tiene en su núcleo una plaza comercial, no explica la morfología longitudinal del nodo. Ello implica que existen otros factores de localización que requieren de mayor análisis pues su morfología no se ajusta a ninguna vía importante. En cambio, la segmentación del nodo Insurgentes Sur, a diferencia de veinte años antes, ha ocasionado que ahora se convierta en un claro corredor comercial sobre la Avenida de los Insurgentes.

Es clara la trascendencia de las plazas comerciales como generadoras de dichos nodos, cuya capacidad de influencia sobrepasa los límites de las AGEB que las contienen. Para el caso de los outlets, parece que son nodos efímeros que representan una transición funcional de zonas industriales. De los tres nodos de 1993, solamente se conserva Tlalnepantla Centro y se crea Vallejo, el cual puede tener el mismo destino de Naucalpan Centro y Torres Lindavista, que ya no 
alcanzaron una significativa concentración de la actividad comercial. Por último, las aglomeraciones de múltiples establecimientos tienden a desaparecer pues, de registrarse cinco nodos en 1993 con dicha cualidad, veinte años después solamente se observan tres. Ello muestra una clara tendencia hacia la procedencia que tendrán las plazas comerciales como generadoras de nodos de una actividad económica que tiende a concentrarse en áreas cada vez más pequeñas.

Esto se refleja en el incremento de los nodos aislados, pues de registrar solamente cinco en 1993, ahora se duplican, de los cuales sólo Interlomas se conserva. El resto de nodos son formaciones nuevas donde la mayoría se explican por la localización de plazas comerciales. Es decir, seis nodos los constituyen las plazas, tres representan una aglomeración de diversos establecimientos (Arcos Bosques, 24 de Abril y Chalco), y Lechería podría clasificarse como outlet, dado que la principal unidad comercial se encuentra en la zona industrial y formalmente es una nave de almacenamiento acondicionada para la venta; no obstante, los productos no son ofrecidos directamente por los fabricantes. Esta reconfiguración de nodos aislados puede vincularse con los cambios en la densidad de la demanda que impone la población residente (Kunz, 2003, p. 56).

Es interesante observar que todos los nodos aislados que se localizan al norte $\mathrm{u}$ oriente de la metrópoli tienen a pie de acceso una ruta de transporte masivo, en atención al segmento de población que utiliza este medio para llegar a los nodos. En contraste, los cuatro nodos de la zona sur-poniente no convergen con ninguna ruta de transporte masivo. En consideración a la localización de la infraestructura de comunicaciones, en términos generales, los nodos aislados tienen un alcance más local, por lo que su localización sobre vialidades principales no es un factor común. Solamente Perinorte, Gran Sur y Buenavista se emplazan sobre una avenida de alcance metropolitano. El resto se ubica sobre avenidas de importancia local, lo que permite intuir su alcance menor a los grandes nodos comerciales. Ello tiene implicaciones en cuanto a la construcción jerarquizada de los nodos comerciales de bienes de consumo duradero, pues se identifican grandes nodos con alcance que podría denominarse supralocal, sin adquirir el carácter metropolitano, y nodos aislados que buscan acercarse a un mercado local. 


\section{Cuadro 3}

Zona Metropolitana de la Ciudad de México:

características generales de las agrupaciones espaciales del comercio de bienes de consumo duradero, 2013

\begin{tabular}{|c|c|c|c|c|c|c|}
\hline \multirow[b]{2}{*}{ Agrupaciones espaciales } & \multicolumn{2}{|c|}{ Valor agregado } & \multicolumn{2}{|c|}{ Area } & \multirow[b]{2}{*}{$\begin{array}{l}\text { Intensidad } \\
\text { producción }^{\mathrm{a}}\end{array}$} & \multirow{2}{*}{$\begin{array}{c}\text { Personal } \\
\text { por unidad } \\
\text { económica }\end{array}$} \\
\hline & $\begin{array}{l}\text { Miles de } \\
\text { millones }\end{array}$ & $\%$ & Hectáreas & $\%$ & & \\
\hline Total de actividad & 64374 & 100.00 & 229706 & 100.00 & 0.28 & 2.90 \\
\hline Total de nodos & 27637 & 42.93 & 4880 & 2.12 & 5.66 & 5.57 \\
\hline 1. Zona Centro & 10588 & 16.45 & 1202 & 0.52 & 8.81 & 4.03 \\
\hline 2. Periférico Sur & 2232 & 3.47 & 501 & 0.22 & 4.45 & 16.34 \\
\hline 3. Satélite & 1930 & 3.00 & 315 & 0.14 & 6.13 & 9.80 \\
\hline 4. Navarte Norte & 1921 & 2.98 & 94 & 0.04 & 20.48 & 12.07 \\
\hline 5. Santa Fe & 1829 & 2.84 & 410 & 0.18 & 4.46 & 16.58 \\
\hline 6. Central de Abasto & 1518 & 2.36 & 380 & 0.17 & 4.00 & 5.67 \\
\hline 7. Tlalnepantla Centro & 1384 & 2.15 & 455 & 0.20 & 3.04 & 9.25 \\
\hline 8. Villa Coapa & 1342 & 2.08 & 100 & 0.04 & 13.35 & 17.19 \\
\hline 9. Del Valle & 1042 & 1.62 & 207 & 0.09 & 5.04 & 12.71 \\
\hline 10. Lindavista & 1040 & 1.61 & 148 & 0.06 & 7.01 & 12.18 \\
\hline 11. Insurgentes Sur & 973 & 1.51 & 121 & 0.05 & 8.03 & 16.29 \\
\hline 12. Vallejo & 704 & 1.09 & 600 & 0.26 & 1.17 & 14.07 \\
\hline 13. San Antonio & 452 & 0.70 & 170 & 0.07 & 2.66 & 14.85 \\
\hline 14. Plaza Aragón & 353 & 0.55 & 86 & 0.04 & 4.09 & 8.60 \\
\hline 15. Chimalistac & 329 & 0.51 & 90 & 0.04 & 3.67 & 7.23 \\
\hline Total de nodos aislados & 3955 & 6.144 & 889 & 0.39 & 4.45 & 10.49 \\
\hline 1. Las Américas & 659 & 1.024 & 160 & 0.07 & 4.12 & 19.13 \\
\hline 2. Interlomas & 572 & 0.89 & 138 & 0.06 & 4.13 & 14.95 \\
\hline 3. Perinorte & 540 & 0.84 & 81 & 0.04 & 6.67 & 15.50 \\
\hline 4. Gran Sur & 476 & 0.74 & 32 & 0.01 & 14.77 & 18.59 \\
\hline 5. Buenavista & 385 & 0.60 & 62 & 0.03 & 6.23 & 10.23 \\
\hline 6. Arcos Bosques & 322 & 0.50 & 157 & 0.07 & 2.04 & 38.80 \\
\hline 7. Paseo Interlomas & 282 & 0.44 & 31 & 0.01 & 9.00 & 20.42 \\
\hline 8. 24 de Abril & 254 & 0.39 & 22 & 0.01 & 11.72 & 5.58 \\
\hline 9. Chalco & 243 & 0.38 & 64 & 0.03 & 3.82 & 2.91 \\
\hline 10. Lechería & 221 & 0.34 & 142 & 0.06 & 1.56 & 15.00 \\
\hline
\end{tabular}

${ }^{\text {a }}$ Se estimó a partir del valor agregado entre superficie y se expresa en miles de millones de pesos sobre hectárea.

Fuente: Elaboración propia a partir del Censo Económico (INEGI, 2014). 


\section{Mapa 3}

Zona Metropolitana de la Ciudad de México: organización territorial de la actividad comercial de bienes de consumo duradero, 2013

99.0ั0

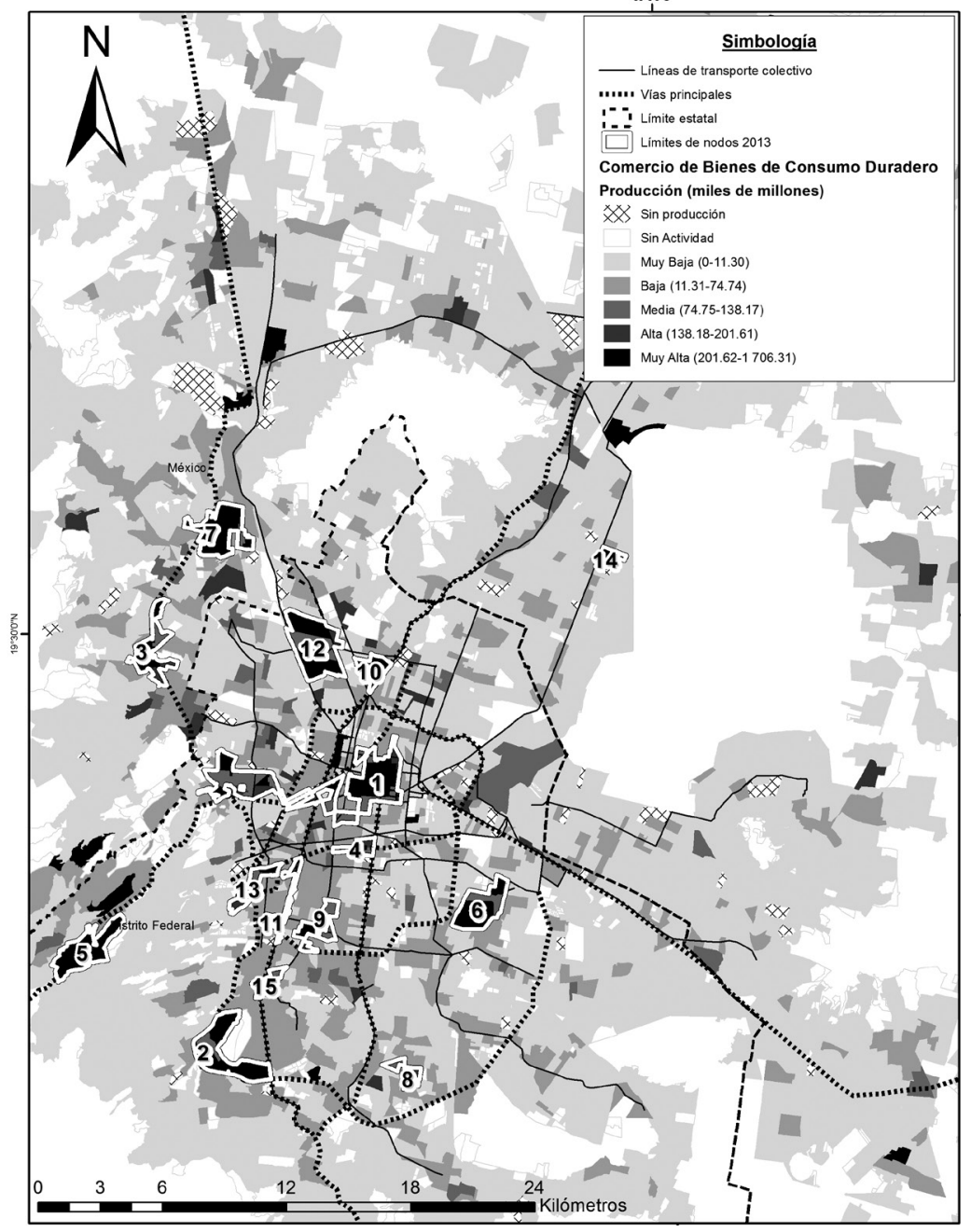

Fuente: Elaboración propia a partir del Censo Económico (INEGI, 2014). 


\section{Descentralización de la actividad comercial}

La actividad comercial de bienes de consumo duradero ha demostrado mantener un patrón concentrado que tiende hacia la segmentación de sus nodos más importantes para dar paso a agrupaciones de menor tamaño. En esta sección se busca entender el nivel de cambio en la producción como resultado del efecto local que pueden tener las condiciones intrínsecas de cada unidad de análisis. Para ello se utiliza la técnica estadística llamada "Cambio y participación”, la cual permite discriminar los cambios generados por la tendencia metropolitana y la sectorial respecto al efecto local.

\section{Cuadro 4}

Zona Metropolitana de la Ciudad de México:

efecto local en el cambio de producción del comercio de bienes de consumo duradero, 1993-2013

\begin{tabular}{lcrrr}
\hline Nivel de cambio & Núm. $\boldsymbol{A G E B}$ & \multicolumn{1}{c}{$\%$} & \multicolumn{1}{c}{ Area } & \multicolumn{1}{c}{$\%$} \\
\hline Total & 5694 & 100.0 & 229706 & 100.0 \\
Decremento alto & 133 & 2.3 & 5352 & 2.3 \\
Decremento medio & 1222 & 21.5 & 42500 & 18.5 \\
Sin cambio & 1136 & 20.0 & 41422 & 18.0 \\
Incremento medio & 3100 & 54.4 & 133083 & 57.9 \\
Incremento alto & 103 & 1.8 & 7348 & 3.2 \\
\hline
\end{tabular}

Fuente: Elaboración propia a partir de los Censos Económicos (INEGI, 1994 y 2014).

Los resultados muestran que la mayoría de la superficie metropolitana tiene una tendencia hacia el incremento medio de la producción comercial, al representar 58\% del área metropolitana. En segunda instancia se encuentran las áreas con un decremento medio, con una superficie de $18.5 \%$. Las áreas que no registraron cambio representan una superficie muy similar, al totalizar $18 \%$ de la superficie urbana. Finalmente, de manera más discreta, se encuentran las zonas con alto incremento y decremento al representar 2 y $3 \%$, respectivamente (Cuadro 4). 


\section{Mapa 4}

Zona Metropolitana de la Ciudad de México: distribución territorial de los cambios en la producción por efecto local de la actividad comercial de bienes de consumo duradero, 1993-2013

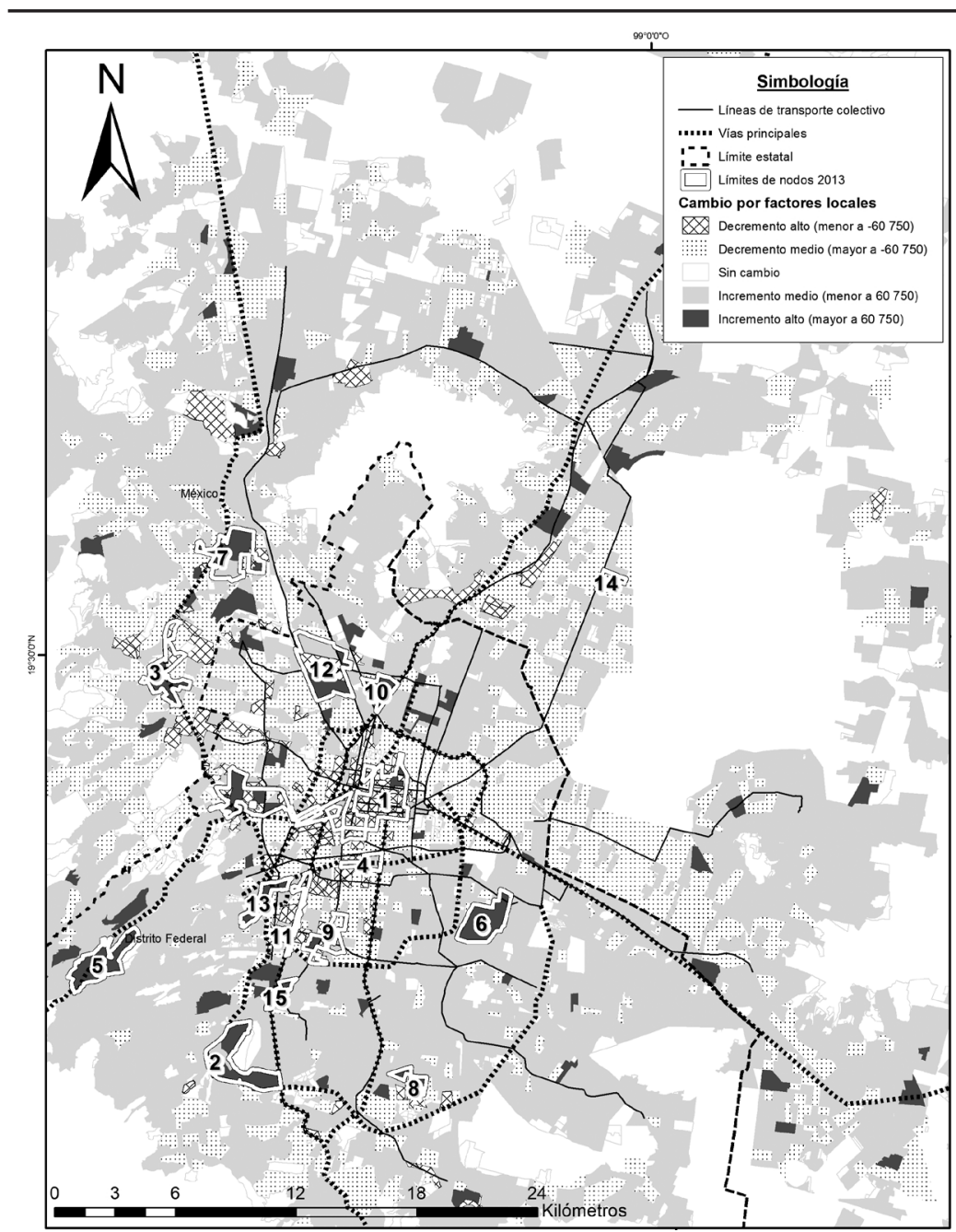

Fuente: Elaboración propia a partir de los Censos Económicos (INEGI, 1994 y 2014). 
Es clara la preponderancia de las áreas que incrementan su actividad comercial; no obstante, existe una tendencia relativamente clara sobre la localización de las zonas con cambio en la producción (Mapa 4). Se observa que el Centro Histórico, que constituye la parte principal del nodo Zona Centro, concentra la mayor parte de las áreas que tuvieron un alto decremento de la producción comercial. Esta zona de alto decremento se extiende hacia la zona sur-poniente, que en 1993 formaba parte del nodo.

Otro patrón identificable es la localización de las áreas que registraron un decremento moderado de la actividad comercial. Se puede ver que alrededor de la zona central existe una preponderancia de este proceso. Este decremento se extiende hasta la zona norponiente, especialmente en el área que separa los nodos del noroeste y el centro metropolitano. Por otro lado, se identifica una ramificación en la zona oriente hasta llegar al extremo este del municipio de Nezahualcóyotl. Complementariamente, la zona de Ecatepec tiene intercaladas zonas de decremento e incremento medio, así como la zona extremo sur de la metrópoli.

Esta evidencia muestra un proceso muy interesante de descentralización con comportamiento diferente en la zona sur respecto a la norte. En la parte sur se identifica una tendencia hacia la concentración en la zona semiperiférica como resultado de la pérdida de la zona central y del extremo sur. En la periferia norte de la metrópoli, vinculada con los municipios conurbados del Estado de México, se observa un incremento más homogéneo de la actividad comercial frente a una pérdida de la zona semiperiférica.

Este patrón diferenciado se puede vincular con las condiciones morfológicas del territorio. Por un lado, la zona sur ha tenido un proceso de expansión más discreto en relación a la zona norte debido a la topografía imperante en cada zona. La zona extremo sur de la metrópoli tiene una topografía que limita la urbanización. Ello implica la generación de colonias poco accesibles con una traza urbana que se ajusta a la topografía local. Estas condiciones de baja accesibilidad física dificultan el desarrollo de las actividades comerciales que están fuertemente enlazadas a las vías de comunicación principales. Asimismo, el poder adquisitivo de los residentes de esta zona no jus- 
tifica la formación de nodos aislados de alcance local, como se observa en la zona poniente de la metrópoli.

En contraparte, la zona norte tiene una superficie más bondadosa para los procesos de urbanización. Ello ha ocasionado que la expansión urbana sea mayor y esté acompañada de la construcción de vías de comunicación que buscan enlazar los municipios conurbados con la zona central. Esto permite intuir que la capacidad de subsistencia de establecimientos comerciales de este tipo puede mantenerse en la zona norte gracias a la accesibilidad física. No obstante, el bajo poder adquisitivo de la población no permite la conformación de importantes nodos comerciales, más que los nodos aislados ya mencionados, como Perinorte, Lechería y Las Américas.

\section{Cuadro 5}

Zona Metropolitana de la Ciudad de México: relación de AGEB entre el nivel de producción en 2013 y de cambio por efecto local de la actividad comercial de bienes de consumo duradero, 1993-2013

\begin{tabular}{cccccc}
\hline Nivel producción & $\begin{array}{c}\text { Decremento } \\
\text { alto }\end{array}$ & $\begin{array}{c}\text { Decremento } \\
\text { medio }\end{array}$ & Sin cambio & $\begin{array}{c}\text { Incremento } \\
\text { medio }\end{array}$ & $\begin{array}{c}\text { Incremento } \\
\text { alto }\end{array}$ \\
\hline Total & 133 & 1222 & 1136 & 3100 & 103 \\
Porcentaje & $100 \%$ & $100 \%$ & $100 \%$ & $100 \%$ & $100 \%$ \\
Sin producción & 9 & 53 & 0 & 1 & 0 \\
Porcentaje & $6.8 \%$ & $4.3 \%$ & $0 \%$ & $0 \%$ & $0 \%$ \\
Sin actividad & 0 & 72 & 1133 & 1 & 0 \\
Porcentaje & $0 \%$ & $5.9 \%$ & $99.7 \%$ & $0 \%$ & $0 \%$ \\
Muy baja & 26 & 938 & 3 & 2682 & 0 \\
Porcentaje & $19.5 \%$ & $76.8 \%$ & $0.3 \%$ & $86.5 \%$ & $0 \%$ \\
Baja & 59 & 142 & 0 & 394 & 15 \\
Porcentaje & $44.4 \%$ & $11.6 \%$ & $0.0 \%$ & $12.7 \%$ & $14.6 \%$ \\
Media & 18 & 13 & 0 & 13 & 34 \\
Porcentaje & $13.5 \%$ & $1.1 \%$ & $0 \%$ & $0.4 \%$ & $33.0 \%$ \\
Alta & 6 & 3 & 0 & 3 & 24 \\
Porcentaje & $4.5 \%$ & $0.2 \%$ & $0.0 \%$ & $0.1 \%$ & $23.3 \%$ \\
Muy alta & 15 & 1 & 0 & 6 & 30 \\
Porcentaje & $11.3 \%$ & $0.1 \%$ & $0 \%$ & $0.2 \%$ & $29.1 \%$ \\
\hline
\end{tabular}

Fuente: Elaboración propia a partir de los Censos Económicos (INEGI, 1994 y 2014). 
Como se había comentado, la mayoría de las áreas registraron un incremento moderado, de las cuales, $86.5 \%$ tienen una producción muy baja (Cuadro 5). Ello muestra un proceso de consolidación de aquellas zonas con muy baja producción; sin embargo, todavía no logran una trascendencia que les permita alcanzar la media urbana. En contraste, las áreas que tuvieron un decremento medio también fueron en su mayoría AGEB con producción muy baja, con un $76.8 \%$ (Cuadro 5), lo cual denota la vulnerabilidad de esta actividad en aquellas zonas con muy discreta producción.

Es muy interesante observar que prácticamente todas las AGEB sin actividad comercial no tuvieron cambio alguno en dicha condición (Cuadro 5). Ello tiene implicaciones muy claras sobre el nulo interés de este tipo de actividad sobre dichas áreas y mercados. Las áreas más pobres tienen una demanda efectiva que no justifica el establecimiento de unidades económicas, por lo que sus habitantes deben realizar mayores recorridos para satisfacer su necesidad de adquirir bienes de consumo duradero (Kunz, 2003, p. 39).

En lo que se refiere al alto decremento, $44.4 \%$ se dio en áreas donde se registra una producción baja. En contraparte, un tercio de las áreas con alto incremento tenían una producción media, y 52.4\% de las AGEB una producción alta y muy alta. Esto se vincula con la concentración de la actividad que se beneficia de la aglomeración, lo que tiene implicaciones en los nodos existentes en 2013, pues la mayoría registra un alto incremento de su producción.

De los 15 nodos identificados en 2013, ocho incrementaron en todas sus AGEB su producción, mientras que siete tuvieron un comportamiento heterogéneo. Primero destacan los nodos de la Zona Centro e Insurgentes Sur, que registraron un alto decremento de su producción, como parte de su segmentación territorial respecto a su configuración en 1993. Nodos como Satélite, Del Valle, Vallejo y Plaza Aragón tuvieron un comportamiento mezclado, donde algunas de sus AGEB mostraron un incremento alto y otras lo opuesto. Ello permite intuir que estos nodos se encuentran en un proceso de transformación o reconfiguración espacial. Por último, Narvarte Norte tuvo un incremento moderado, lo cual muestra una estabilidad en su producción.

Esta condición de alto incremento en los nodos se expresa de forma más clara en los nodos aislados. En este caso, ocho de los diez 
tuvieron un alto incremento, siendo solamente Interlomas y Buenavista los que registraron un incremento medio. Ello refuerza la tendencia hacia la formación de nodos comerciales que se posicionan de manera contundente bajo la lógica del policentrismo, pero hacia una segmentación de nodos con muy alta producción, con muy discreto tamaño, y posicionados esencialmente en una zona semicentral del área urbana.

\section{Conclusiones: segmentación polinuclear del comercio de bienes de consumo duradero}

La organización territorial del comercio de bienes de consumo duradero muestra un claro patrón policéntrico con una mayor presencia de nodos en la zona poniente de la zona metropolitana. En concordancia al postulado de Dematteis y Governa (2001, p. 29) sobre la trascendencia del desarrollo del transporte automotor como motivador de la descentralización territorial de la actividad económica, se evidencia que todos los nodos se enlazan con una vialidad de importancia metropolitana, destacando la trascendencia de la Avenida de los Insurgentes y de Anillo Periférico.

De igual forma, Dematteis y Governa afirman que el proceso de descentralización territorial deriva en una disminución de importancia del tradicional centro urbano hasta su desaparición. Este proceso puede observarse en este estudio al identificar una pérdida clara de participación del nodo central en cuanto a extensión y producción. Asimismo, la mayoría de los nodos tienden a posicionarse en la zona semiperiférica de la metrópoli. No obstante, el nodo central sigue siendo el más importante a escala metropolitana, por lo que no se observa que en un plazo corto desaparezca.

El nodo central y el de Insurgentes Sur -el segundo de mayor trascendencia en cuanto a producción y extensión- han mostrado un proceso de segmentación, lo cual nuevamente refuerza la propuesta de Dematteis y Governa sobre la formación de concentraciones cada vez más pequeñas no solamente en proporción a la ciudad cada vez más extensa, sino también en términos absolutos. Por ejemplo, en 1993 la extensión promedio de los once nodos fue de 515 hectáreas y 
en suma dichos nodos abarcaban 5665 hectáreas. En 2013, los quince nodos promediaban una superficie de 325 hectáreas y todos totalizaban 4880 hectáreas. Ello demuestra una clara tendencia hacia la construcción de más nodos, pero más pequeños.

Ante los nuevos procesos de urbanización, a partir de la lógica del libre mercado, es posible identificar una presencia contundente de proyectos inmobiliarios que determinan la formación de nodos comerciales en la ZMCM. Lo que Lerner (2005) denomina acupuntura urbana, se vincula con el impacto que tiene el modelo norteamericano del mall $^{8}$ en la mayoría de los nodos, al fortalecer la concentración de la actividad comercial, sin que necesariamente toda su producción se efectúe en el interior de estos centros comerciales. Estos megaproyectos tienen la capacidad de atraer empresas comerciales tanto en su interior como en un área de influencia. Este proceso denota lo que Gasca (2017, p. 77) denomina como "transición progresiva de sistemas tradicionales a formatos empresariales", donde los centros comerciales representan una modalidad de financiarización de la edificación urbana a partir de su inserción en el mercado inmobiliario. ${ }^{9}$

Esta lógica de concentración responde a las tradicionales economías de aglomeración, en especial a las de localización, pues este tipo de comercio responde a condiciones muy específicas vinculadas a la accesibilidad metropolitana que otorgan contadas vías vehiculares debido a que requieren una baja frecuencia de los consumidores para satisfacer sus necesidades. Esto permite una mayor concentración de la actividad pues la gente está dispuesta a hacer un viaje especial para el consumo de dichos bienes. Este viaje puede volverse multipropósito gracias a la concentración de este tipo de comercio. Adicionalmente, la diferencia territorial y socioeconómica de la distribución de la población fomenta un mayor atractivo en deter-

${ }^{8}$ El principal atributo de los centros comerciales se vincula con la lógica de las economías de aglomeración de la actividad comercial, donde se concentran empresas minoristas y se generan espacios multifuncionales de consumo (Gasca, 2017, p. 74).

${ }^{9}$ Gasca (2017) reconoce el papel de los centros comerciales en la consolidación de corredores comerciales y áreas de concentración de actividad terciaria. De los 221 centros comerciales identificados por el autor hasta $2016,18 \%$ se encuentran en algún nodo de trascendencia metropolitana. 
minadas zonas de las urbes, especialmente en donde predomina la población de mayor poder adquisitivo.

Por lo tanto, retomando como base la teoría del lugar central se puede construir un modelo jerarquizado de esta actividad comercial. Al reconocer las diferencias socioeconómicas de la población y la fragmentación funcional que tiene la metrópoli actual, es que este modelo tiende a una transformación a partir de los postulados desarrollados por Davies (1972) y Potter (1980). Se retoma la afirmación de Davies (1972, p. 69) sobre el papel del centro de mayor jerarquía donde es posible encontrar bienes de diferente calidad. Para el caso de la ZMCM, se reconoce el nodo de la Zona Centro con dicha atribución.

Es decir, se identifica el patrón policéntrico de la actividad comercial de bienes de consumo duradero, pero la Zona Centro sigue siendo la más importante, con una clara diferencia en producción respecto a los nodos subsiguientes pues genera cinco veces más valor agregado que el segundo nodo identificado. Asimismo, el nodo central tiene una variedad de establecimientos que ofrecen una calidad diferenciada de bienes. En la zona oriente, y que corresponde con el Centro Histórico, se encuentran múltiples establecimientos que ofrecen productos accesibles para la mayoría de la población. En contraste, la zona poniente, conocida como Polanco, agrupa gran cantidad de boutiques, que ofrecen productos de alto precio. Esta cualidad se esquematiza en la Esquema 3, donde se observa una diferenciación en cantidad y tamaño de los establecimientos en estos centros de segundo rango. ${ }^{10}$

En el tercer rango se encuentran grandes nodos como Periférico Sur, Satélite, Santa Fe y Central de Abasto, de los cuales sólo el último se encuentra en la zona centro-oriente. Esta diferenciación responde a la lógica que Potter (1980, p. 209) relaciona con la propensión de la población de alto nivel socioeconómico para realizar

${ }^{10}$ Cushman y Wakefield (2016, p. 46) reconocen que las calles de Avenida Madero en el Centro Histórico y Avenida Presidente Masaryk en Polanco generan los mayores precios de renta comercial, aun por encima de los centros comerciales más exitosos, como Centro Comercial Perisur, que forma parte del nodo Periférico Sur, y como Plaza Antara, también ubicada en Polanco. 
viajes más largos para acceder a los centros comerciales, en comparación con la población de menor ingreso. Ello deriva en una mayor dispersión de la actividad comercial en la zona oriente, mientras que en la zona poniente se identifica una mayor presencia de nodos de diversos tamaños que, de acuerdo con Kunz (2003, p. 40), responden a un esquema de fuerte competencia en el que buscan apropiarse del mercado a partir de una combinación de productos y servicios. Esto se refleja también en la localización de los nodos aislados, los cuales también predominan en la zona poniente. En el Esquema 3 se plasma esta cualidad mediante un incremento de centros de tercer rango en el segmento de la población de clase alta, en contraste con la gran cantidad de nodos de quinto rango que atienden a la población de nivel socioeconómico bajo.

Respecto a la morfología de los nodos, destaca la formación de los corredores comerciales. Este tipo de concentración muestra la trascendencia de las vías de comunicación para el emplazamiento y formación de la concentración comercial de bienes de consumo duradero. Siguiendo la categoría de Berry (1971, p. 361), es posible encontrar las cuatro tipologías. Por un lado, se tienen las calles tradicionales como Paseo de la Reforma, vía que enlaza las dos secciones del nodo central. Avenida de los Insurgentes entra en la categoría de concentraciones en arterias urbanas. El corredor de Santa Fe se clasifica como una de las nuevas franjas suburbanas. Periférico Sur y Satélite se desarrollan a lo largo del Anillo Periférico, lo cual las clasifica como corredores sobre vías rápidas orientadas. Aunque el autor caracteriza estas últimas a partir de los outlets, en este caso son nuevamente las plazas comerciales las que determinan su localización.

Es un hecho que se identifica un equilibrio en las fuerzas centrípetas y centrífugas a una escala metropolitana al permanecer de manera más o menos estable el grado de concentración. El nodo central mantiene su trascendencia metropolitana y los nodos secundarios se localizan en la zona semiperiférica. La única diferencia es la proliferación de nodos aislados en la zona periférica, que pueden estar vinculados con la consolidación urbana que permite la formación de mercados de tamaño suficiente que justifican estos nuevos nodos locales. 


\section{Esquema 3}

Propuesta de modelo

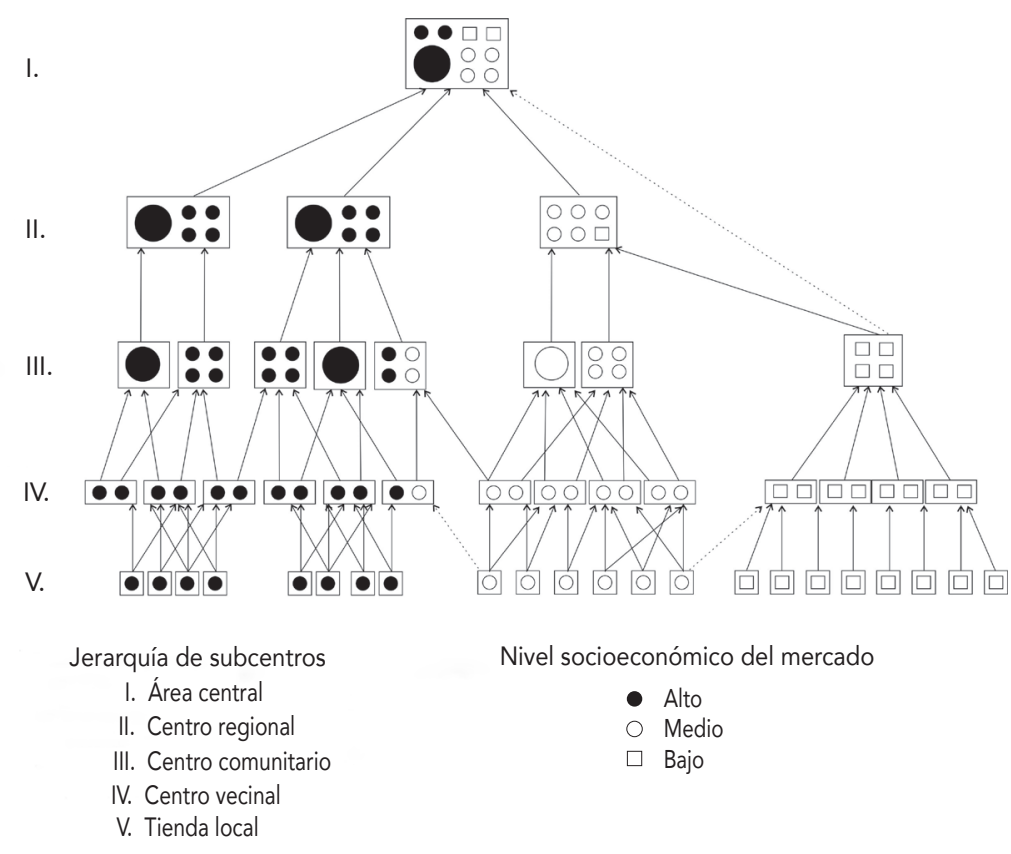

Fuente: Elaboración propia.

Muy diferente se observa la convergencia de fuerzas centrípetas y centrífugas a escala local, pues es evidente la segmentación de los nodos que se reducen significativamente de tamaño, lo que implica una disminución de fuerza centrípeta o de su alcance espacial. Esto sin dudas refleja una dinámica dual, donde la concentración metropolitana se mantiene, pero la escala de influencia de los nodos disminuye. Ello marca una tendencia interesante que requiere de un continuo análisis como resultado de la constante expansión del área urbana y el crecimiento de mercados nuevos en su periferia. 


\section{Bibliografía}

Aguilar, A. y Mateos, P. (2011). Diferenciación sociodemográfica del espacio urbano de la Ciudad de México. Eure, Revista Latinoamericana de Estudios Urbanos Regionales, 37(110), 5-30. https://scielo.conicyt.cl/scielo.php?script=sci_arttext\&pid $=\mathrm{S} 0250-71612011000100001$

Banco de México. (2019). Glosario. El Banco de México. Ciudad de México. http://www.anterior.banxico.org.mx/divulgacion/glosario /glosario.html\#S

Berry, B. (1971). Internal structure of the city. En L. Bourne (ed.), General features of urban commercial structure (pp. 361-367). Toronto: Oxford University Press.

Borsdorf, A. (2003). Cómo modelar el desarrollo y la dinámica de la ciudad latinoamericana. Eure, Revista Latinoamericana de Estudios Urbanos y Regionales, 29(86), 37-49. https://scielo.conicyt.cl/scielo.php?script=sci_arttext\&pid $=\mathrm{S} 0250-71612003008600002$

Burgess, R. (2011). Determinismo tecnológico y fragmentación urbana: un análisis crítico. En E. Pradilla Cobos (comp.), Ciudades compactas, dispersas, fragmentadas (pp. 63-98). Ciudad de México: Universidad Autónoma Metropolitana / Porrúa.

Celis, F. y Pantaleón, I. (2016). Clase media mexicana, imán para las inversiones en centros comerciales. Forbes México. https://www. forbes.com.mx/clase-media-mexicana-iman-las-inversiones -centros-comerciales/

Christaller, W. (1966). Central places in southern Germany. Englewood Cliffs, NJ: Prentice-Hall.

Conapo. (1994). Evolución de las ciudades de México, 1900-1990. Ciudad de México: Consejo Nacional de Población.

Cushman y Wakefield (2016). Main streets across the world. Londres: Cushman and Wakefield Research Publication. http://www. cushmanwakefield.mx/en/research-and-insight/2015/mainstreets-across-the-world-2015

Davies, R. (1972). Structural models of retail distribution. Analogies with settlement and urban land-use theories. Transactions of the 
Institute of British Geographers, 57, 59-82. https://www.jstor. org/stable/621554?seq=1\#metadata_info_tab_contents

Dematteis, G. y Governa, F. (2001). Urban form and governance: The new multi-centred urban pattern. En H. Andersson, G. Jorgensen, D. Joye y W. Ostendorf (eds.), Change and stability in urban Europe: Form, quality and governance (pp. 27-45). Aldershot, Londres: Ashgate.

Forbes, J. (1972). Central place theory. An analytical framework for retail structure. Land Economics, 48(1), 15-22. https://www. jstor.org/stable/3145635?seq=1\#metadata_info_tab_contents

Garza, G. (2008). Macroeconomía del sector servicios en la Ciudad de México, 1960-2003. Ciudad de México: El Colegio de México, A.C.

Gasca, J. (2017). Centros comerciales de la Ciudad de México: el ascenso de los negocios inmobiliarios orientados al consumo. Eure, Revista Latinoamericana de Estudios Urbanos y Regionales, 43(130), 73-96. https://scielo.conicyt.cl/pdf/eure/v43n130/02507161-eure-43-130-0073.pdf

Gaschet, F. (2002). The new intra-urban dynamics: Suburbanisation and functional specialisation in French cities. Papers in Regional Science, 81(1), 63-81. https://link.springer.com/article/10.1007/ s101100100088

Grajales, G. (2006). Microestructuración del sector servicios de la Ciudad de México. En G. Garza (coord.), La organización espacial del sector servicios en México (pp. 457-500). Ciudad de México: El Colegio de México, A.C.

Harris, C. y Ullman, E. (1945). The nature of cities. The Annals of the American Academy of Political and Social Science, 242, 7-17. https://www.jstor.org/stable/1026055?seq=1\#metadata info tab contents

Hoyt, H. (1939). The structure and growth of residential neighborhoods in American cities. Washington, DC: Federal Housing Administration.

INEGI. (1994). Censo Económico. Aguascalientes, México: Instituto Nacional de Estadística y Geografía. https://www.inegi.org.mx/ programas/ce/1994/ 
INEGI. (1999). Metodología, censos económicos 1999. Aguascalientes, México: Instituto Nacional de Estadística y Geografía. https://www.inegi.org.mx/app/biblioteca/ficha.html?upc $=702$ 825168377

INEGI. (2004). Metodología para las actividades del sector industrias manufactureras. Aguascalientes, México: Instituto Nacional de Estadística y Geografía. https://www.inegi.org.mx/app/ biblioteca/ficha.html?upc $=702825049997$

INEGI. (2014) Censo Económico. Aguascalientes, México: Instituto Nacional de Estadística y Geografía. https://www.inegi.org.mx/ programas/ce/2014/

Kohsaka, H. (1986). The location process of central place system within a circular city. Economic Geography, 62(3), 254-266. https://www.tandfonline.com/doi/abs/10.2307/144009

Kunz, I. (2003). Comercio. En I. Kunz (coord.), Usos del suelo y territorio. Tipos y lógicas de localización en la Ciudad de México (pp. 21-81). Ciudad de México: Plaza y Valdés.

Lang, R. (2003). Edgeless cities exploring the elusive metropolis. Washington, D.C: Brookings Institution Press.

Lerner, J. (2005). Acupuntura urbana. Barcelona: Record.

Link, F. (2008). De la policentralidad a la fragmentación en Santiago de Chile. Centro-h, Revista de la Organización Latinoamericana y del Caribe de Centros Históricos, 2, 13-24. https://biblio. flacsoandes.edu.ec/catalog/resGet.php?resId=14414

Lynch, K. (1981). A theory of good city form. Cambridge, MA: MIT Press.

Munizaga, G. (2000). Macroarquitectura. Tipología y estrategias de desarrollo urbano. Ciudad de México: Alfaomega.

Potter, R. (1980). Spatial and structural variations in the quality characteristics of intra-urban retailing centres. Transactions of the Institute of British Geographers, 5(2), 207-228.

Prévôt, M. (2001). Fragmentación espacial y social: conceptos y realidades. Perfiles Latinoamericanos, 10(19), 33-56. http://perfil esla.flacso.edu.mx/index.php/perfilesla/article/view/315

Ramajo, J. y Márquez, M. Á. (2008). Componentes espaciales en el modelo Shift-Share. Una aplicación al caso de las regiones peninsulares españolas. Estadística Española, 50(168), 247-272. 
Sedesol, Conapo e INEGI. (2012). Delimitación de las zonas metropolitanas de México 2010. Ciudad de México: Secretaría de Desarrollo Social / Consejo Nacional de Población / Instituto Nacional de Estadística y Geografía

Simmons, J., Kamikihara, S. y Garrocho, C. (2016). La estructura del comercio al por menor en la Ciudad de México, 2011. En A. G. Aguilar (coord.), La Ciudad de México en el siglo XXI. Realidades y retos (pp. 415-424). Ciudad de México: Miguel Ángel Porrúa / Gobierno de la Ciudad de México.

Trullén, J. y Boix, R. (2003). Barcelona, metrópolis policéntrica en red. (Documento de trabajo, núm. 03.03). Barcelona: Universidad Autónoma de Barcelona.

West, D., Hohenbalken, B. y Kroner, K. (1985). Tests of intraurban central place theories. The Economic Journal, 95(377), 101117. https://academic.oup.com/ej/article-abstract/95/377/101/51 90734?redirectedFrom=fulltext

Yang, W. (1990). The context of Beijing's commercial network -an empirical study on the central place model. GeoJournal, 21(1-2), 49-55. https://link.springer.com/article/10.1007/BF00645307

\section{Acerca del autor}

Fermín Alí Cruz Muñoz es doctor en Estudios Urbanos y Ambientales por El Colegio de México, A.C. Sus líneas de investigación son: localización de la actividad económica, desarrollo inmobiliario y habitabilidad urbana. Es miembro del Sistema Nacional de Investigadores, nivel I. Actualmente es profesor investigador del Centro de Investigaciones Económicas, Administrativas y Sociales del Instituto Politécnico Nacional. ORCID: https://orcid.org/0000-0001-70577057

Entre sus publicaciones se encuentran:

Cruz-Muñoz, F. (2018). Evolution of the space concepts in locational theories of intraurban economic activity. GeoJournal, 18(6), 1271-1284. https://link.springer.com/article/10.1007/s10708-0179832-5 
Cruz-Muñoz, F. (2018). Organización microespacial del comercio de bienes de consumo inmediato en la región metropolitana de la Ciudad de México (1993-2013). Revista de Geografia Norte Grande, 71, 125-145. https://scielo.conicyt.cl/scielo.php?script =sci_abstract\&pid=S0718-34022018000300125\&lng=es\&nr$\mathrm{m}=\mathrm{iso}$

Cruz-Muñoz, F. y Isunza, G. (2017). Construcción del hábitat en la periferia de la Ciudad de México. Estudio de caso en Zumpango. Eure, Revista Latinoamericana de Estudios Urbano Regionales, 43(129), 187-207. https://scielo.conicyt.cl/scielo.php?script=sci_ abstract\&pid $=$ S0250-71612017000200009\&lng=es\&nrm $=$ iso

Recepción: 24 de julio de 2019. Aceptación: 4 de noviembre de 2019. 